\title{
The Freiburg approach to ethics consultation: process, outcome and competencies
}

Stella Reiter-Theil University Hospital, Albert Ludwigs University, Freiburg

\begin{abstract}
The paper describes how ethics consultation can be valuable to health professionals, patients and their families in understanding and evaluating ethical values and their consequences in a particular situation. Ethics consultation as it is practised at the university hospital of Freiburg is a special professional service offered by members of an academic institution. The practical approach and the goals are illustrated by a case study showing the difficulties of deciding about the limitation of intensive care medicine after heart surgery in the setting of maximum treatment. Here, the ethics consultation was initiated by the relatives of the patient who wanted a decision to withhold further life-sustaining treatment.

Following the experiences in Freiburg, it is concluded that clinical ethicists have to cover a variety of relevant fields of knowledge, need special analytical skills, and should have professional competence in counselling, including conflict mediation or crisis intervention.

(Fournal of Medical Ethics 2001;27 supp1 I:i21-i23)

Keywords: Ethics consultation; case study; limitation of treatment; family involvement; qualification
\end{abstract}

\section{Background and context of the Freiburg approach}

Freiburg is one of the few places in Germany where a university hospital has made the considerable commitment of establishing its own Centre for Ethics and Law in Medicine (ZERM). The author, as medical ethicist and research coordinator of this centre, has been able to build a multidisciplinary team which is engaged in a clinical research programme across a number of clinical disciplines. Members of the centre offer ethics case consultation as part of the research programme. The various settings for these consultations have been described in detail elsewhere.

There has been a particular interest in ethical issues arising in the context of intensive care. The systematic documentation of such issues, together with the analysis of these cases, is carried out in much more detail as part of a research programme than is the case in the more routine case consultations in other clinical settings. This level of detail has been made possible because of national grants (principally from the German Research Council and the Robert Bosch Foundation). This connection between practical ethics support and clinically relevant research which is approved by major national funding bodies has contributed to the acceptability of clinical ethics both in the university and in the hospital.

Freiburg University Hospital has several years' experience of clinical ethics consultation as a result of ZERM and has never established a clinical (hospital) ethics committee. There are two possible reasons for this. First, the ethics support provided by the centre, which works closely with the research ethics committee of the medical faculty, may already be providing the ethics support needed. Second, establishing a formal committee may be seen as too bureaucratic a response to the problem of ethics support. By contrast, the support offered by the centre is accessible and responsive. It is also varied. In addition to case consultation members of the centre are involved in the ethics education, not only of students in the university, but also of hospital staff. Centre members have initiated ethics rounds-like "Grand Rounds" but focusing on the ethical rather than the purely medical aspects of management. Furthermore, in carrying out case consultation, members of the research programme take a central role in documenting the analysis and outcome of the consultation. Thus the centre seems to do much of the work that might be expected of a committee, and in a way that is closely connected with clinical practice. ${ }^{2}$ Various models of ethics support have been discussed at meetings of the Network for Clinical Ethics Consultation. [AG Klinische Ethik-Konsultation, for information please contact the author.] One of the most interesting programmes in clinical ethics in Germany is at the Teaching Hospital Gilead, Bielefeld. This programme, like the one in Freiburg, offers clinical ethics support without a clinical ethics committee, but on the grounds of developing special competencies.

\section{Ethics consultation in the clinical setting-a case study}

I will describe the approach to ethics case consultation taken by ZERM by giving the example of a real, but somewhat changed case. The patient is a man in his late seventies who has diffuse cerebral damage following heart surgery. He has clouding of consciousness and is unable to communicate. It is unclear whether there is a chance left for his consciousness and communication to recover. 
The legal position in Germany with regard to patients unable to take part in management decisions is complex. Family members of a previously competent adult patient can only make treatment decisions if they have been formally authorised to do so in advance by the patient, or by a court or by both. In the absence of such authorisation, or of an advance directive the presumed wishes of the patient are relevant if there is any way of knowing them. Here, the relatives may play an important role in reporting from the patient's life. If this is not possible, then the patient's best interests should be pursued in the light of medical criteria.

\section{PROCESS}

Two ethics consultations took place. The first was prior to surgery and had been initiated by the cardiac surgeon. An ethicist met with the cardiac surgeon. The surgeon wanted to discuss the question of whether the cardiac surgery should be undertaken in the first place in the light of the critical health status of the patient. The outcome of that consultation was that surgery was in the patient's best interests although it was recognised that it might not be successful. Although the ethicist suggested involving the relatives directly, this suggestion was not acted upon and the relatives were simply informed of the decision by the doctor, as was learned later.

The second consultation was initiated a few weeks after surgery by the patient's closest relatives, who contacted the author. A consultation was set up for a few days later, and in the meantime a colleague prepared a summary of the history to help with the consultation. The relatives had written to the cardiac surgeon's medical director complaining that they thought the patient was not being cared for in the correct manner.

The participants in the consultation were: the attending cardiac surgeon; a nurse; three relatives of the patient; a close friend of the patient who was not a relative, and two ethicists. The consultation was initially chaired by the surgeon. He explained the management plan that had been drawn up and implemented and responded defensively to the letter from the relatives. In his view everything ought be done to maximise the chance of as good a recovery as possible. His position, he thought, was in accord with the recent guidelines, Guidelines for Medical Aid in Dying, issued by the German Medical Association in $1998 .^{3}$ According to these guidelines the therapeutic goal need no longer be towards cure if such a cure is no longer attainable. He did not think the time had yet come to give up the goal of cure. The atmosphere in the consultation was tense. A conflict between the surgeon and the relatives over the appropriateness of continuing to strive for cure was felt rather than articulated. The relatives had little opportunity to express their views.

ETHICS FOCUS

At this stage one of the ethicists intervened. She suggested that since this was specifically an ethics consultation, and one which had been requested by the relatives, it might be more appropriate for one of the ethicists to chair the meeting and to focus it more on the ethical issues. A more traditional clinical discussion could take place after the ethicists left, if that was what was wanted. Accordingly one of the ethicists took over the chairing of the meeting. She structured the meeting so as to allow each person first to share his or her view on the present situation, then to outline the factors in the past that seemed relevant, and the important next steps.

The surgeon's view was as summarised above. The relatives felt the patient's current state was unbearable for him. They felt the most important thing at this stage was that the patient should be allowed to die with dignity. They said they thought the patient would not want to be kept alive under the present circumstances. The ethicists focused on helping to clarify the relatives' concerns and the points of conflict between their views and those of the surgeon. They also explicitly raised the issue of the letter the relatives had written to the surgeon's medical director. The focus then shifted to the difficulties each side had in understanding and accepting the ethical attitudes of the other party. This led to increased understanding and respect for each others' motivations. By this stage the atmosphere had become much more cooperative and there was sufficient sharing of fundamental goals to aim towards a consensus.

\section{The outcome of the consultation}

The ethical arguments of the people involved were explicitly formulated and elaborated until a mutual understanding was achieved. Some of the medical misunderstandings of the relatives were corrected. A consensus was reached that one of the relatives should formally be appointed, by a court, as legal guardian, able to act as substitute decision maker on behalf of the patient. This enabled more focused communication between the doctors and relatives, and allowed this relative to become involved fully in decision making. The formal appointment of a relative as legal guardian also allowed for this person to be fully involved as a partner in decision making.

It was also agreed that the therapeutic goal should be conceived in terms of palliative rather than curative care. It was explicitly elaborated that this change was accepted in the light of the German Guidelines for Medical Aid in Dying. ${ }^{3}$ The importance to the relatives of dying with dignity was recognised and accepted by the cardiac surgeon.

\section{Lessons for the future-competencies}

Reaching consensus about limitations of treatment with patients unable to express their own views may be difficult in the German context. Our experience suggests that ethics consultation can be valuable to health professionals, patients and their families in a number of ways. First, ethicists can introduce ways 
of analysing the ethical aspects of patient care that are helpful in coming to consensus. Second, ethicists can provide some information about relevant codes and the law. Third, the language of ethics can serve as a common language in which conflicting viewpoints can be discussed.

But, effective case consultation requires additional professional skills. Such consultation often takes place when there is conflict between different people or groups of people. Ethicists may need to be able to be effective in conflict mediation, psychological counselling and, occasionally, crisis intervention. ${ }^{145}$

Here are five conclusions from my experience with ethics case consultation:

1) Take sensitive fields such as end-of-life issues seriously even when colleagues try to avoid dealing with them.

2) Communicate with, and help, others to find ways to express their ethical values and goals.

3) Create a context for patients and relatives to prepare for ethical challenges such as end-of-life care planning.

4) Try to develop or benefit from ethics consultation; it may be helpful for conflict resolution.
5) Collaborate in specific clinical ethics research programmes if possible; they contribute to our knowledge and help to improve clinical ethics support services.

Stella Reiter-Theil, Privatdozentin, PhD, Dipl-Psych, is a Medical Ethicist, Research Coordinator of the Center for Ethics and Law in Medicine (ZERM), and Senior Lecturer in Medical Ethics in the Medical Faculty of Albert Ludwigs University, Freiburg, Germany.

\section{References}

1 Reiter-Theil S. Ethics consultation on demand: concepts, practical experiences and a case study. Fournal of Medical Ethics 2000;26:198-203.

2 Gillon R. Clinical ethics committees-pros and cons. Fournal of Medical Ethics 1997;23:203-4.

3 Bundesärztekammer, Grundsätze zur ärztlichen Sterbebegleitung. [Guidelines for medical aid in dying. Deutsches $A$ ra 1998; 95: A-2367.

4 American Society for Bioethics and Humanities. Core competencies for health care ethics consultation. Glenview, Illnois: ASBH, 1998 .

5 Reiter-Theil S. Ethik in der Klinik-Theorie für die Praxis: Ziele, Aufgaben und Möglichkeiten des Ethik-Konsils. [Ethics in the hospital - theory for practice: goals, tasks and chances of ethics consultation.] Ethik in der Medizin 1999;11:222-32.

\section{Journal of Medical Ethics supplement-Clinical Ethics Committees}

Additional copies of this supplement are available for only $£ 10$ (UK) and $£ 12$ (outside of the UK).

To order your copy/ies please call +44(0)20 73836270 or fax +44(0)2073836402. 